\title{
How gamma-band oscillatory activity participates in encoding of naturalistic stimuli in random networks of excitatory and inhibitory
} neurons

\author{
Alberto Mazzoni*1, Nicolas Brunel ${ }^{2,1}$ and Stefano Panzeri ${ }^{3,1}$
}

\begin{abstract}
Address: ${ }^{1}$ Division of Statistical Physics, Institute for Scientific Interchange, Turin, Italy, ${ }^{2}$ Laboratoire de Neurophysique et Physiologie, Universite Paris Descartes, 3CNRS-UMR8119, Paris, France and ${ }^{3}$ Brain and Cognitive Sciences Department, Italian Institute of Technology, Genoa, Italy

Email: Alberto Mazzoni* - mazzoni@isi.it

* Corresponding author
\end{abstract}

from Seventeenth Annual Computational Neuroscience Meeting: CNS*2008

Portland, OR, USA. 19-24 July 2008

Published: II July 2008

BMC Neuroscience 2008, 9(SuppI I):PII5 doi:I0.II86/I47I-2202-9-SI-PII5

This abstract is available from: http://www.biomedcentral.com/I47I-2202/9/SI/PII5

(C) 2008 Mazzoni et al; licensee BioMed Central Ltd.

Recent experiments suggest that in V1 information about natural scenes is encoded in gamma band and low frequency Local Field Potentials (LFPs) [1]. To understand which features of the stimuli are encoded in these frequency bands and how they are encoded, we analyzed how a model of a cortical network responded to various types of simulated stimuli.

The network was a randomly connected network of excitatory and inhibitory neurons, that can exhibit both asynchronous and synchronous irregular activity, in which the global activity oscillates in time with a frequency that depends both on synaptic time constants and on the excitation/inhibition balance [1]. The LFP was modeled as a linear combination of excitatory and inhibitory currents. This choice allows us to reproduce the dependence of the LFP spectrum on frequency and contrast as recorded in vivo [2].

We first considered the responses of the network to Poisson random inputs with various levels of time-independent intensity. We found that the intensity modulates the power of the gamma band of LFPs, in agreement with experimental results [2]. When we used input stimuli characterized by a sinusoidally varying firing rate of low frequency $(<20 \mathrm{~Hz})$, modulations in the input were transformed into LFP modulations with the same frequency and with a power inversely proportional to the frequency itself. Thus, low frequency LFPs encoded the information about input low frequency modulations. In contrast, the gamma band LFPs encoded information about the overall spike rate of the input.

We then considered the network responses to a dynamic 'naturalistic' stimulus based on real spike trains from LGN neurons recorded from anesthetized monkeys watching movies [3]. We found that the mutual information conveyed by the LFP power about the different movie scenes has two pronounced peaks, at low frequency and in the high gamma band, with approximately the same peak height. As expected from the analysis with simple stimuli, we found a correlation between the power of low frequencies in each input interval and the power of the same frequencies in the corresponding output interval, and between the input intensity and the output gamma power.

This suggests that, under natural stimulation, low frequency cortical LFPs encode slow variations in the input, whereas gamma LFPs encode the total input spike count. Since stimulus-to-stimulus variations of input spike count and input slow oscillations are only very weakly related under natural viewing, low-frequency and high-frequency LFPS encoded largely independent information.

\section{References}

I. Brunel N, Wang XJ: What determines the frequency of fast network oscillations with irregular neural discharges? I. Synaptic dynamics and excitation-inhibition balance. J Neurophysiol 2003, 40:4I5-430. 
2. Henrie JA, Shapley R: LFP power spectra in VI cortex: The graded effect of stimulus contrast. I Neurophysiol 2005, 94:479-490.

3. Montemurro MA, Rasch MJ, Murayama Y, Logothetis NK, Panzeri S: Phase-of-firing coding of natural visual stimuli in primary visual cortex. Curr Biol in press.

Publish with Bio Med Central and every scientist can read your work free of charge

"BioMed Central will be the most significant development for disseminating the results of biomedical research in our lifetime. " Sir Paul Nurse, Cancer Research UK

Your research papers will be:

- available free of charge to the entire biomedical community

- peer reviewed and published immediately upon acceptance

- cited in PubMed and archived on PubMed Central

- yours - you keep the copyright

Submit your manuscript here:

http://www.biomedcentral.com/info/publishing_adv.asp 